\title{
$\beta$-Catenin: A Metazoan Filter for Biological Noise?
}

\author{
Saba Rezaei-Lotfi 1,2, Neil Hunter ${ }^{1,2}$ and Ramin M. Farahani 1,2* \\ ${ }^{1}$ IDR/Westmead Institute for Medical Research, Sydney, NSW, Australia, ${ }^{2}$ Faculty of Medicine and Health, University of \\ Sydney, Sydney, NSW, Australia
}

Molecular noise refers to fluctuations of biological signals that facilitate phenotypic heterogeneity in a population. While endogenous mechanisms exist to limit genetic noise in biological systems, such restrictions are sometimes removed to propel phenotypic variability as an adaptive strategy. Herein, we review evidence for the potential role of $\beta$-catenin in restricting gene expression noise by transcriptional and post-transcriptional mechanisms. We discuss mechanisms that restrict intrinsic noise subsequent to nuclear mobilization of $\beta$-catenin. Nuclear $\beta$-catenin promotes initiation of transcription but buffers

OPEN ACCESS

Edited by:

Moisés Santillán,

Center for Research and Advanced Studies (CINVESTAV), Mexico

Reviewed by:

Luis Diambra,

National University of La Plata,

Argentina

Guillermo Rodrigo,

Spanish National Research

Council (CSIC), Spain

Raul Guantes,

Autonomous University of Madrid,

Spain

*Correspondence:

Ramin M. Farahani

ramin.mostofizadehfarahani@sydney.

edu.au

Specialty section:

This article was submitted to

Systems Biology,

a section of the journal

Frontiers in Genetics

Received: 24 May 2019

Accepted: 20 September 2019

Published: 16 October 2019

Citation:

Rezaei-Lotfi S, Hunter $N$ and Farahani RM (2019) $\beta$-Catenin: A Metazoan Filter for Biological Noise?

Front. Genet. 10:1004.

doi: 10.3389/fgene.2019.01004 against the resultant noise by restraining transcription elongation. Acceleration of cell cycle, mediated via Wnt/ $\beta$-catenin downstream signals, further diminishes intrinsic noise by curtailing the efficiency of protein synthesis. Extrinsic noise, on the other hand, is restricted by $\beta$-catenin-mediated regulation of major cellular stress pathways.

Keywords: $\beta$-catenin, biological noise, transcriptional regulation, cell cycle, translational regulation

\section{INTRODUCTION}

In biological systems, noise can be defined as variability in transmission of a signal between two sources. The variability often manifests in the unpredictability of emergence of a certain outcome. Such unpredictability is a direct consequence of variations in biological signals that maintain the genotype/phenotype continuum. Within physiological limits, phenotypic heterogeneity that is driven by biological noise enriches the population and provides a basis for natural selection. It must be emphasized, however, that phenotypic heterogeneity mediated by noise contrasts sharply, and acts synergistically, with encoded (genotypic) heterogeneity. While genetic noise could propel phenotypic diversity in the absence of genotypic differences, the existence of such genomic variability amplifies the impact of noise.

Non-encoded induction of heterogeneity by genetic noise facilitates adaptation to stressors. Induction of competence in Bacillus subtilis is a prime example of such noise-mediated adaptation to stressors (Spizizen, 1958). In the transient state of competence, B. subtilis internalizes exogenous DNA and integrates it into the genome. Suel et al. demonstrated that competence corresponds to an unstable state that is driven by stressor-mediated induction of gene expression noise while the competent cells eventually return to the non-competent state (Suel et al., 2006). Similar to prokaryotes, genetic noise is instrumental in development of metazoans. Spatial patterning of the retinal color-vision mosaic during development of Drosophila melanogaster is instructed by stochastic transcriptional bursts that invoke probabilistic resolution of dichotomous fate outcomes (Mikeladze-Dvali et al., 2005). It becomes evident that induction or suppression of genetic noise is strictly regulated. Notably, molecular mechanisms that regulate gene expression noise in metazoans remain largely unknown. Herein, we review the evidence for regulation of gene expression noise by a major cytoskeletal protein, $\beta$-catenin. 


\section{BIOLOGICAL DEFINITION OF NOISE}

Broadly, molecular noise refers to processes that introduce stochasticity into monostable deterministic outcomes in a cell or a population of cells (Samoilov et al., 2005; Samoilov et al., 2006). In this review, however, noise refers to cell-cell variability of gene expression, measured at protein level, as originally proposed by Elowitz et al. (2002). Therefore, noise in synthesis of a particular protein can be defined as the standard deviation divided by the average concentration of that protein (signal) in a population of cells. Gene expression noise can be classified into two broad categories based on the origin as extrinsic noise or intrinsic noise (Raser and O'Shea, 2005). Intrinsic noise results from fluctuations of biological signals that occur within an individual cell as the signal is generated or transmitted (Figure 1A). These fluctuations are cumulative consequences of the inherent stochasticity of transcription dynamics, post-transcriptional interactions and translational variability, (Julicher and Bruinsma, 1998) that alter the strength of a biological signal independent of external influences. Stochastic events, such as replication-transcription conflict (Garcia-Muse and Aguilera, 2016) and RNA polymerase backtracking mediated by R-loop formation (Skourti-Stathaki, 2014), are examples of events that invoke intrinsic noise in an individual cell. Broadly, extrinsic noise refers to cellcell variability in gene expression that is communicated by fluctuations in other cellular components (e.g., RNA polymerase availability, mitochondrial activity, etc.) and affects multiple genes at the same time (Volfson et al., 2006). In the present context, extrinsic noise may be induced by exogenous events, e.g., environmental stressors (Mitosch et al., 2017). Herein, we discuss the activities of $\beta$-catenin in regulating extrinsic and intrinsic noise separately. Prior to such discussion, an overview of $\beta$-catenin activity and signaling is provided.

\section{$\beta$-CATENIN STRUCTURE AND ACTIVITY}

Catenin- $\beta$ is a cytoskeletal protein with dual functionality; apart from stabilization of the cytoskeleton, it is involved in the regulation of transcription (MacDonald et al., 2009). As a cytoskeletal protein, $\beta$-catenin binds to cadherin-based junctional complexes and stabilizes physical association of adherens junctions and the cytoskeleton (McCrea et al., 1991; Brembeck et al., 2006; Nelson, 2008). Unbound free cytoplasmic $\beta$-catenin is tightly regulated by a destruction complex that recruits the protein and degrades it subsequent to phosphorylation by Gsk-3 $\beta$ (Wu and Pan, 2010). Due to constant degradation, $\beta$-catenin has a short half-life of $\approx 1 \mathrm{~h}$ (Salic et al., 2000). Free cytoplasmic $\beta$-catenin can, however, escape phosphorylation and subsequent degradation. Upon stimulation by Wnt, disheveled interferes with activity of the destruction complex (Fiedler et al., 2011). Subsequently, rescued free $\beta$-catenin is shuttled into the nucleus where it binds to the trans-activation partner, TCF3/LEF1 (Behrens et al., 1996) to activate transcription from specific genomic loci ( $\mathrm{He}$ et al., 1998). Nuclear localization of $\beta$-catenin and the resultant trans-activation are two parallel events that synergistically regulate intrinsic and extrinsic noises in gene expression.

\section{MODULATION OF INTRINSIC TRANSCRIPTIONAL NOISE BY $\beta$-CATENIN}

Intrinsic noise in gene expression results from probabilistic variation in transcriptional and translational outputs. Transcription-related noise manifests as stochastic amplification or attenuation of transcriptional output, independent of the stimulus that has triggered the initiation of transcription. Such variability can occur during initiation or elongation steps of transcription. At the initiation stage, promoter-driven fluctuations of RNA polymerase-II (RNAP-II) activity are a major source of intrinsic noise (Raser and O'Shea, 2005; Blake et al., 2006). The promoter fluctuations lead to bursts of transcription initiation and enhance the likelihood of cell-cell variability among a group of identical cells (Blake et al., 2006). However, inefficient transcription elongation could buffer such promoter-driven intrinsic noise by restricting the flow-on effect on downstream transcripts (Raser and O'Shea, 2005). It is by strategic positioning at the interface of transcription initiation and elongation that $\beta$-catenin can regulate intrinsic transcriptional noise (Figure 1B).

$\beta$-catenin reshapes the global transcriptional landscape by reducing processivity of RNAP-II (Daugherty et al., 2014). Inhibition of RNAP-II occurs by combined activities of $\alpha$-catenin and $\beta$-catenin that does not affect promoter loading of the transcriptional initiation complex. Altered processivity of RNAP-II and the resultant inefficiency of transcription reduces transcriptional noise by diminishing the global availability of transcripts and buffering the transcribed mRNAs against promoter-driven fluctuations during transcription initiation (Ko, 1991; Raser and O'Shea, 2004; 2005). Combined activities of $\alpha$-catenin and $\beta$-catenin can also attenuate global transcriptional activity by non-canonical induction of DNA double-stranded DNA breaks (Serebryannyy et al., 2017). The repair of DNA damage could delay transcription by $\approx 30 \mathrm{~min}$ in non-homologous end-joining and $\approx 7 \mathrm{~h}$ in homologous recombination (Mao et al., 2008). This is a significant delay as the rate of transcription is 10 to $100 \mathrm{nt} / \mathrm{s}$, and thus, it takes $\approx 10 \mathrm{~min}$ for a mammalian gene of $10 \mathrm{kbp}$ to be transcribed (Shamir et al., 2016). Negative regulation of transcription elongation by induction of DNA cleavage could powerfully reduce the global transcriptional profile, and hence, the intrinsic noise in gene expression that results from fluctuations of promoter activity. $\beta$-Catenin can also curtail transcriptional activity via binding to the chromatin remodeling factor, CHD8 (Thompson et al., 2008). By these activities $\beta$-catenin controls bursts of transcriptional output. However, degradation of transcripts (Houseley and Tollervey, 2009) could also introduce cell-cell variability in gene expression. Notably, $\beta$-catenin regulates the stability of mature transcripts (Ross, 1996). This particularly applies to transcripts, such as cyclooxygenase-2 (COX-2), that are constantly and rapidly degraded by default and are only stabilized in acute phase responses, such as inflammation. $\beta$-catenin interacts 


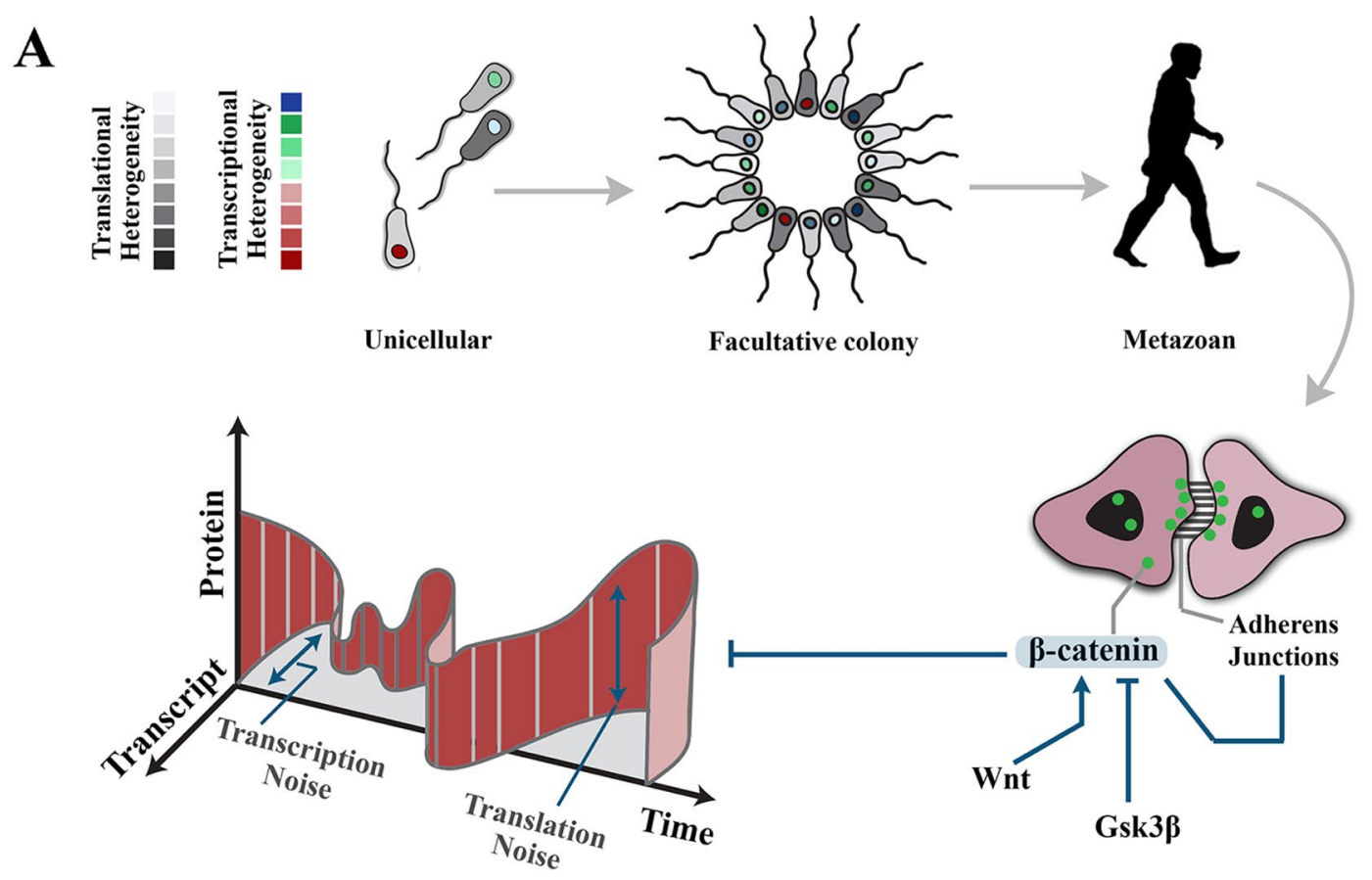

B
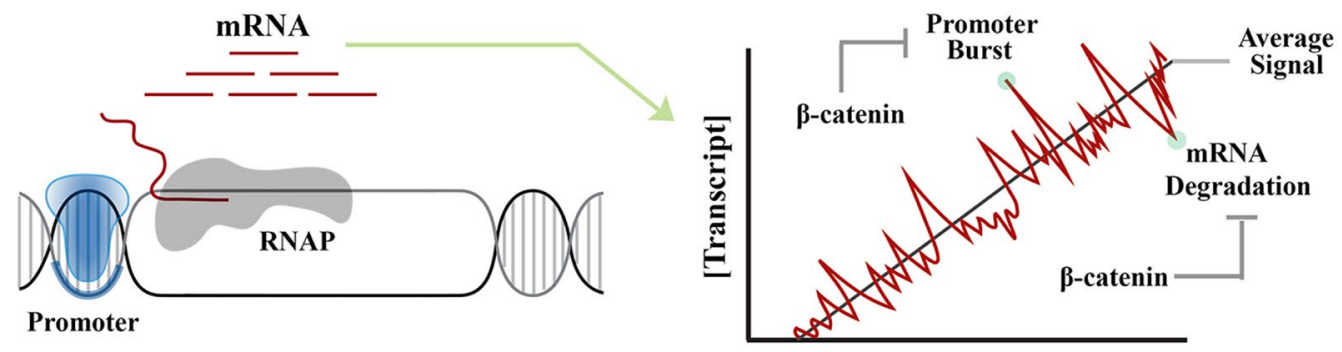

Promoter

Time
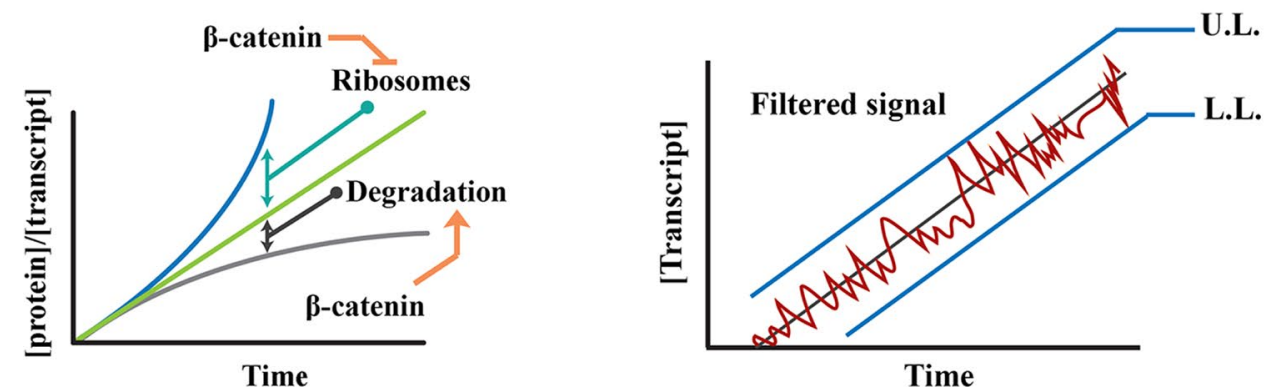

FIGURE 1 | Regulation of intrinsic noise via $\beta$-catenin occurs at various levels during transmission of a signal. (A) Transition from unicellular life forms into multicellularity was predicated upon existence of mechanisms that regulate gene expression noise during developmental self-organization. The evolution of $\beta$-catenin not only facilitated cell-cell communication and multicellular self-organization but also provided a mechanism to control gene expression noise at transcription and translation levels. (B) Images demonstrate rising concentration of a transcript after activation of the associated promoter. Stochastic events, such as promoter-driven transcriptional burst or mRNA degradation, could potentially alter transcript availability, independent of upstream events that induce the signal, and lead to noise in transmitted signals. Likewise, increased efficiency of ribosomal translation and post-translational degradation of a protein (e.g., by autophagy) could alter the ratio of transcript to protein and introduce noise into the system. Interactions of $\beta$-catenin reduce transcription-related noise by buffering against promoter-driven transcriptional bursts and stabilizing mRNAs (right). As such, $\beta$-catenin stabilizes upper and lower limits of transcriptional noise. Further, $\beta$-catenin reduces translation-related noise by shortening G1 phase (and hence curtailing protein synthesis) and amplifying protein degradation (lower left). UL, upper limit; LL, lower limit. 
with the 3'-untranslated region of several key transcripts leading to stabilization of the mRNA and resultant restriction of transcriptional noise (Briata et al., 2003; Lee et al., 2007).

By these mechanisms, $\beta$-catenin reduces cell-cell variability and hence the standard deviation of molecular signals in a population. Reduction of the standard deviation can be interpreted as establishing the upper and lower limits of transcriptional noise. In other words, standard deviation (S) of a protein copy number $\left(\mathrm{x}_{\mathrm{i}}\right)$ in a population of cells would approach a minimum $\left(\mathrm{S}_{\min }\right)$ if the copy numbers in individual cells converge toward a central value:

$$
\begin{gathered}
S=\sqrt{\frac{1}{n-1} \sum_{i=1}^{n}\left(x_{i}-\bar{x}\right)^{2}} \\
\min \left(x_{i}\right) \rightarrow \bar{x} \& \max \left(x_{i}\right) \rightarrow \bar{x} \Rightarrow S \rightarrow S_{\text {min }}
\end{gathered}
$$

The lower limit $\left(\min x_{\mathrm{i}}\right)$ is established by stabilizing the transcribed mRNAs. The upper limit $\left(\max x_{\mathrm{i}}\right)$ is maintained by $\beta$-catenin-mediated buffering of transcriptional bursts as described above.

\section{MODULATION OF TRANSLATIONAL NOISE BY $\beta$-CATENIN}

The transcription factor c-Myc (c-myelocytomatosis oncogene) is one of the key genes that is trans-activated by $\beta$-catenin signaling (He et al., 1998). Myc, in turn, stimulates transcription of genes involved in growth and proliferation (Zeller et al., 2006). It is, therefore, not surprising that ribosome biogenesis and global protein synthesis are controlled by transcriptional activity of Myc (van Riggelen et al., 2010). Myc binds to E-box sequences in the promoters of active rDNA clusters and directly regulates the RNAPI-mediated transcription of $18 \mathrm{~S}, 5.8 \mathrm{~S}$, and 28S rRNAs (Grandori et al., 2005). Myc also orchestrates RNAPII-mediated transcription of ribosomal proteins (Boon et al., 2001). In addition, translation initiation factors, eIF4E, eIF2 $\alpha$, eIF4AI, and eIF4GI, are regulated by transcriptional activity of c-Myc (Schmidt, 2004). While efficient translation is known to invoke translational noise (Ozbudak et al., 2002), coupling of such efficient translation to $\mathrm{G} 1$ shortening (Farahani et al., 2019) restricts and reduces noise. This is because feedback from ribosome biogenesis is integrated into cell cycle and controls accelerated progression through G1 phase of cycle (Bernstein et al., 2007). $\beta$-catenin is the key molecule that couples ribosome biogenesis and cell cycle dynamics, as explained below.

Upon association of $\beta$-catenin with DNA-binding partners, repressive activity of TCF/LEF transcription factors is abolished, and transcription is initiated (Wu et al., 2012). Two major drivers of G1 phase of cell cycle, cyclin-D1 (Shtutman et al., 1999) and c-Myc (He et al., 1998), are among those genomic loci trans-activated by nuclear $\beta$-catenin. As such, enhanced $\beta$-catenin signaling accelerates interphase by shortening G1 phase of cycle (Figures 2A, B). A further corollary of such activity is that it improves synchronicity of a cycling population (Dokumcu et al., 2018; Farahani et al., 2019). Synchronized and accelerated cycling has two important consequences (Figure 2). Synchronicity of cycling reduces population-level variability and genetic noise that results from such variability (Pauklin and Vallier, 2013). Further, acceleration of cycle by shortening of G1 reduces the length of time that individual cells spend in the "noisy" G1 phase of cycle (Figures 1B and 2).

Shortening of G1 phase can reduce translation-related noise by another parallel mechanism. A major source of translationrelated noise is temporal oscillation of the key E3 ubiquitin ligase complexes that regulate cell cycle: anaphase-promoting complex (APC/C), and Skp, Cullin, F-box-containing complex (SCF complex) (Vodermaier, 2004). The APC/C complex is active during M/G1 phases, and the SCF complex regulates S/G2 phases of cycle in a mutually exclusive manner. While the range of substrates directed to degradation by the APC/C complex is restricted (Thornton and Toczyski, 2003), the SCF complex has a broader substrate recognition capacity. As such, it is expected that noise would be suppressed more efficiently by SCF-mediated post-translational degradation of substrates during S/G2 phases. Therefore, it can be concluded that a truncated G1 induced by enhanced $\beta$-catenin signaling could potentially reduce translation-related noise (Farahani et al., 2019) by two parallel mechanisms, global reduction of protein synthesis and amplified ubiquitin-mediated protein degradation. $\beta$-catenin can also directly enhance degradation of other proteins by acting as an adaptor protein.

While $\beta$-catenin is a major target of glycogen synthase

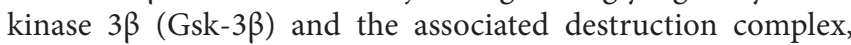
other substrates are also directed to proteosomal degradation by activity of this complex (Kim et al., 2009). These include the cytoskeletal proteins $\alpha$-actin, tenascin, myosin regulatory light chain, ribosomal proteins, such as rpL30 and some kinases, e.g., serine-threonine kinase-35. The specific role of $\beta$-catenin in this process is best illustrated by post-translational depletion of Hippo cascade mediators. Two important mediators of Hippo signaling cascade, Yap and Taz (Meng et al., 2016), participate in formation of the $\beta$-catenin destruction complex (Azzolin et al., 2014). Therefore, in $\mathrm{Wnt}^{\text {off }}$ cells, $\beta$-catenin acts as an adaptor that directs post-translational degradation of Hippo cascade mediators and hence reduces noise in this signaling pathway. In addition to interaction with intrinsic sources of noise, the buffering capacity of $\beta$-catenin is bolstered by its particular mode of communication with extrinsic inducers of gene expression noise.

\section{EXTRINSIC INDUCERS OF NOISE INTERFACE WITH $\beta$-CATENIN}

On route to degradation, $\beta$-catenin is enzymatically altered by proteins including Gsk-3 $\beta$ that also sense cellular stress. Therefore, activation of stress adaptation pathways in response to genetic noise (Spizizen, 1958) could potentially modulate 


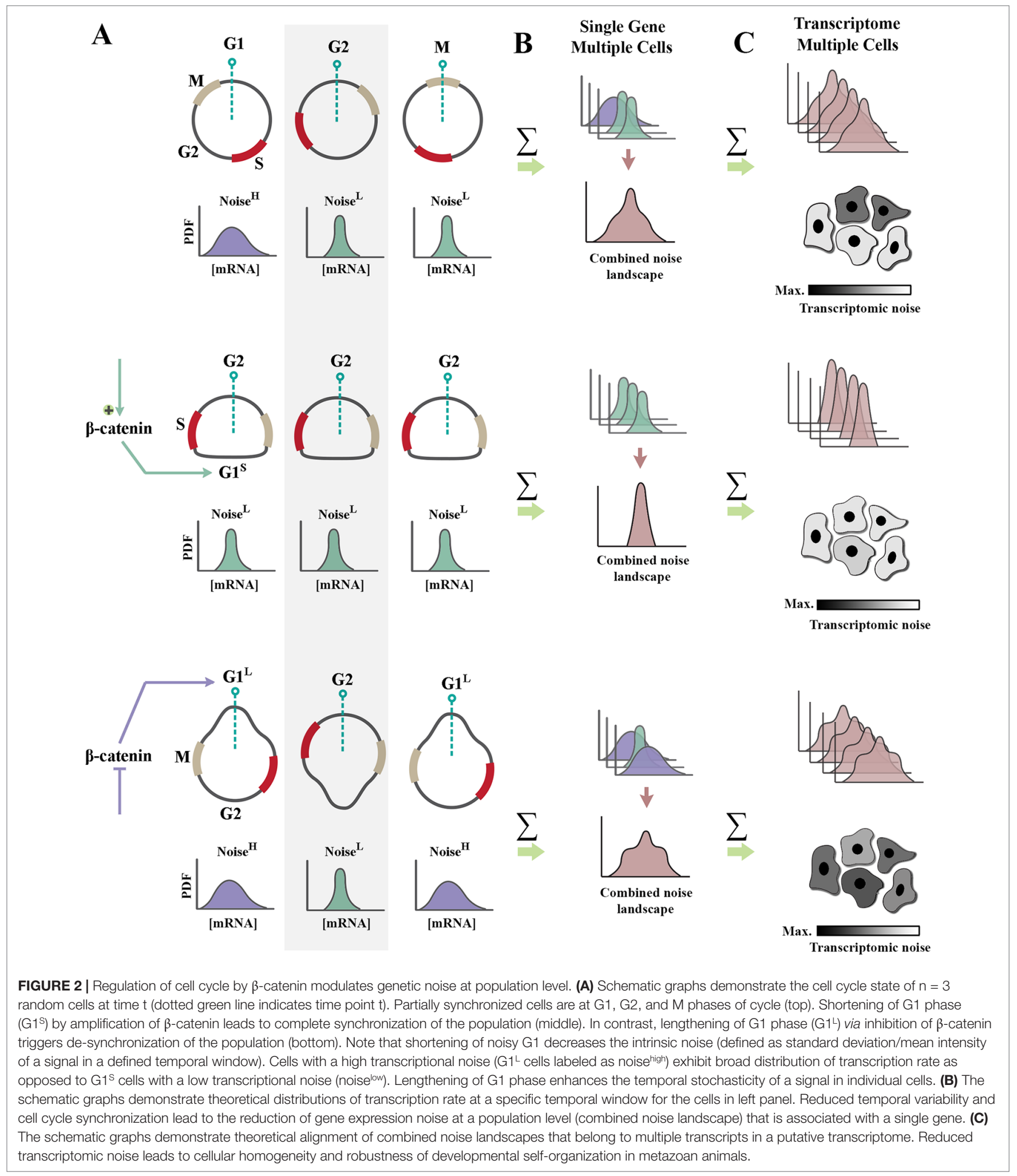

availability of $\beta$-catenin, as discussed below. In mammalian cells, stressors are sensed by Gsk-3 $\beta$ (Maurer et al., 2014), mammalian target of Rapamycin (mTOR) (Aramburu et al., 2014), and NF-kb (Mercurio and Manning, 1999) pathways. As noted previously,
Gsk-3 $\beta$ is a major component of the $\beta$-catenin destruction complex (Wu and Pan, 2010). Stressors such as hypoxia (Roh et al., 2005) activate Gsk-3 $\beta$ leading to a reduced level of free cytoplasmic $\beta$-catenin. In parallel, stress-mediated inhibition of 
mTOR activity (Xie et al., 2011) enhances autophagic flux (Jung et al., 2010) and leads to depletion of cytoplasmic $\beta$-catenin by autophagy (Kuhn et al., 2015). Signaling by NF-kb, a sensor for oxidative stress (Schreck et al., 1992), results in ubiquitination and subsequent degradation of $\beta$-catenin (Chang et al., 2013). Hence, in response to stressors that exceed a certain threshold, e.g., DNA damage, free cytoplasmic $\beta$-catenin is depleted (Sadot et al., 2001) and cell cycle is arrested in the noise-prone G1 phase (Agarwal et al., 1995).

\section{TRANSCRIPTIONAL REWIRING ENHANCES BUFFERING OF EXTRINSIC NOISE BY $\beta$-CATENIN}

Cascade-level associations with other signaling pathways remarkably amplify the capacity of $\beta$-catenin in buffering genetic noise (Supplementary Figure 1). Herein, a few examples are provided. Downstream to TGF- $\beta$ signaling, Smad-3 rescues $\beta$-catenin from degradation and assists nuclear localization of this protein (Zhang et al., 2010). Once in the nucleus, Smad-3 partners with Tcf/Lef to activate downstream targets of the $\mathrm{Wnt} / \beta$-catenin signaling cascade (Aloysius et al., 2018). However, Smad-3 is also required for the antagonistic Notch-1 signaling pathway (Blokzijl et al., 2003; Zavadil et al., 2004). As such, association of Smad-3 with activated $\beta$-catenin will diminish the available pool of Smad-3 that can interact with Notch-1 and will lead to a reduced Notch-1 signaling output. Given the inhibitory impact of Notch-1 on $\beta$-catenin (Kwon et al., 2011), attenuation of Notch-1 signaling further amplifies the noise-filtering capacity of $\beta$-catenin. Sonic hedgehog signaling is another major partner of $\beta$-catenin. Not only do both Gsk $3 \beta$ and CK1 $\alpha$ phosphorylate Gli3 (downstream mediator of Sonic hedgehog) (Tempe et al., 2006) but also the phosphorylated protein is recognized and degraded by $\beta$-TrCP generating the truncated Gli3R (Wang and Li, 2006), a trajectory that closely replicates that of $\beta$-catenin degradation. Further, released Gli3R inhibits $\beta$-catenin transcriptional activity by direct interaction with the C-terminal domain (Ulloa et al., 2007). Upon activation of $\beta$-catenin by inhibition of the associated destruction complex, the negative impact of GliR will also be abolished. In turn, this amplifies the noise-buffering activity of $\beta$-catenin. Activation of Hedgehog signaling can also suppress p53, a major inhibitor of $\beta$-catenin (Sadot et al., 2001), by activating Mdm2 (Abe et al., 2008). It may be concluded that network-level wiring of $\beta$-catenin to other signaling cascades moderates its activity and provides an excess capacity that could be unleashed to repress gene expression noise with higher efficiency.

\section{WNT AS AN AMPLIFIER OF NOISE BUFFERING CAPACITY}

As mentioned previously, binding of Wnt ligands to the associated receptor $\left(\mathrm{Wnt}^{\text {on }}\right)$ blocks the destruction of $\beta$-catenin and enhances noise buffering capacity of the protein under special circumstances (Arias and Hayward, 2006). During ontogeny, this amplification of noise dampening becomes critical in temporal windows where genetic noise is not tolerated. The segmentation clock, for example, is tightly controlled by combined activities of Wnt and Notch signaling cascades during somitogenesis (Blokzijl et al., 2003; Zavadil et al., 2004). (Pourquie, 2003). As such, gene expression noise in the temporal domain could obscure the sharp boundary of segments due to interference in temporal oscillations of developmental cascades. In agreement with this notion, fuzzy somite boundaries are a major consequence of impaired Wnt signaling (Aulehla et al., 2003).

\section{MEDICAL IMPLICATIONS OF ALTERED NOISE BUFFERING}

Altered regulation of gene expression noise is an efficient prosurvival strategy utilized by neoplastic cells to resist applied therapies (Brock et al., 2015). Amplified noise enhances phenotypic heterogeneity and survival capacity of neoplastic cells in parallel to, but independent of, genotypic divergence (Spencer et al., 2009). Noise also improves phenotypic plasticity of neoplastic cells and their transformation into more resistant subtypes (Brock et al., 2015). MicroRNA-mediated amplification of signaling by $\beta$-catenin efficiently overrides and represses noise and cell-cell variability in cancer cells (Dokumcu et al., 2018). It is notable that the latter noise buffering activity of $\beta$-catenin overrides the cellular heterogeneity that arises from mutational heterogeneity of neoplastic cells (Dokumcu et al., 2018). As such, exogenous regulation of gene expression noise may provide a therapeutic opportunity to reprogram the sensitivity (Spencer et al., 2009) of neoplastic cells and reduce recurrence rates following therapy (Dokumcu et al., 2018).

\section{EVOLUTIONARY REMARKS}

From an evolutionary perspective, the activity of $\mathrm{Wnt} / \beta$-Catenin in buffering genetic noise is compatible with the ancestral function of this cascade. Wnt ligands interact with Frizzled receptors to activate the downstream signaling cascade. Frizzled receptors share the basic structural organization of $G$ protein-coupled receptors (GPCRs) (Malbon, 2004). In yeast, GPCRs control the mating pathway that is used for sexual reproduction (Dohlman and Thorner, 2001). During sexual reproduction, secreted pheromones interact with GPCRs and activate expression of pheromone-responsive genes, leading to growth arrest and synchronization of the entire population into the opposite mating type (Bardwell, 2004). In addition to population-level synchronization, repression of growth-related genes minimizes genetic noise at an individual cell level (Bardwell, 2004). Interestingly, there is significant overlap between components of the yeast pheromone response pathway and the metazoan Wnt cascade (Bardwell, 2004). Further, Frizzled receptors can replace yeast GPCRs and stimulate the yeast mating response pathway in the absence of added Wnt ligands thereby leading 
to synchronization of the entire population (Dirnberger and Seuwen, 2007).

\section{CONCLUDING REMARKS}

It may be concluded that evolution of $\beta$-catenin, in addition to its documented role in organization of cytoskeleton, provided metazoan life forms with a capacity to modulate gene expression noise. Buffering of noise is required to stabilize the evolutionary adaptations that characterize various species. This feature, referred to as Waddington's canalization (Siegal and Bergman, 2002), improves developmental robustness and hence the chance of survival of a species. While it remains to be proven, it is tempting to postulate that $\beta$-catenin may play a central role in canalization of developmental traits. This proposition is aligned to the recent findings demonstrating that $\beta$-catenin regulates self-organization of neural progenitor cells (Rezaei-Lotfi et al., 2019). Buffering of gene expression noise via $\beta$-Catenin could enhance robustness of developmental self-organization.

\section{REFERENCES}

Abe, Y., Oda-Sato, E., Tobiume, K., Kawauchi, K., Taya, Y., Okamoto, K., et al. (2008). Hedgehog signaling overrides p53-mediated tumor suppression by activating Mdm2. Proc. Nat. Acad. Sci. U.S.A. 105 (12), 4838-4843. doi: 10.1073/pnas.0712216105

Agarwal, M. L., Agarwal, A., Taylor, W. R., and Stark, G. R. (1995). p53 controls both the G2/M and the G1 cell cycle checkpoints and mediates reversible growth arrest in human fibroblasts. Proc. Nat. Acad. Sci. U.S.A. 92 (18), 84938497. doi: 10.1073/pnas.92.18.8493

Aloysius, A., DasGupta, R., and Dhawan, J. (2018). The transcription factor Lef1 switches partners from beta-catenin to Smad3 during muscle stem cell quiescence. Sci. Signal. 11 (540). doi: 10.1126/scisignal.aan3000

Aramburu, J., Ortells, M. C., Tejedor, S., Buxade, M., and Lopez-Rodriguez, C. (2014). Transcriptional regulation of the stress response by mTOR. Sci. Signal. 7 (332), re2. doi: 10.1126/scisignal.2005326

Arias, A. M., and Hayward, P. (2006). Filtering transcriptional noise during development: concepts and mechanisms. Nat. Rev. Genet. 7 (1), 34-44. doi: $10.1038 / \operatorname{nrg} 1750$

Aulehla, A., Wehrle, C., Brand-Saberi, B., Kemler, R., Gossler, A., Kanzler, B., et al. (2003). Wnt3a plays a major role in the segmentation clock controlling somitogenesis. Dev. Cell. 4 (3), 395-406. doi: 10.1016/S1534-5807(03)00055-8

Azzolin, L., Panciera, T., Soligo, S., Enzo, E., Bicciato, S., Dupont, S., et al. (2014). YAP/TAZ incorporation in the beta-catenin destruction complex orchestrates the Wnt response. Cell 158 (1), 157-170. doi: 10.1016/j.cell.2014.06.013

Bardwell, L. (2004). A walk-through of the yeast mating pheromone response pathway. Peptides 25 (9), 1465-1476. doi: 10.1016/j.peptides.2003.10.022

Behrens, J., von Kries, J. P., Kuhl, M., Bruhn, L., Wedlich, D., Grosschedl, R., et al. (1996). Functional interaction of beta-catenin with the transcription factor LEF-1. Nature 382 (6592), 638-642. doi: 10.1038/382638a0

Bernstein, K. A., Bleichert, F., Bean, J. M., Cross, F. R., and Baserga, S. J. (2007). Ribosome biogenesis is sensed at the start cell cycle checkpoint. Mol. Biol. Cell. 18 (3), 953-964. doi: 10.1091/mbc.e06-06-0512

Blake, W. J., Balazsi, G., Kohanski, M. A., Isaacs, F. J., Murphy, K. F., Kuang, Y., et al. (2006). Phenotypic consequences of promoter-mediated transcriptional noise. Mol. Cell. 24 (6), 853-865. doi: 10.1016/j.molcel.2006.11.003

Blokzijl, A., Dahlqvist, C., Reissmann, E., Falk, A., Moliner, A., Lendahl, U., et al. (2003). Cross-talk between the Notch and TGF-beta signaling pathways mediated by interaction of the Notch intracellular domain with Smad3. J. Cell. Biol. 163 (4), 723-728. doi: 10.1083/jcb.200305112

Boon, K., Caron, H. N., van Asperen, R., Valentijn, L., Hermus, M. C., van Sluis, P., et al. (2001). N-myc enhances the expression of a large set of genes functioning

\section{AUTHOR CONTRIBUTIONS}

RF: conception of the work. SR-L and RF: extensive literature search and manuscript drafting. NH and RF: critical revision of the work. $\mathrm{RF}$ and $\mathrm{NH}$ : final version approval.

\section{FUNDING}

This study was supported by NIDCR Grant R01 DE015272 and Australian National Health and Medical Research Council Grant 512524.3 .

\section{SUPPLEMENTARY MATERIAL}

The Supplementary Material for this article can be found online at: https://www.frontiersin.org/articles/10.3389/fgene.2019.01004/ full\#supplementary-material

in ribosome biogenesis and protein synthesis. EMBO J. 20 (6), 1383-1393. doi: 10.1093/emboj/20.6.1383

Brembeck, F. H., Rosario, M., and Birchmeier, W. (2006). Balancing cell adhesion and Wnt signaling, the key role of beta-catenin. Curr. Opin. Genet. Dev. 16 (1), 51-59. doi: 10.1016/j.gde.2005.12.007

Briata, P., Ilengo, C., Corte, G., Moroni, C., Rosenfeld, M. G., Chen, C. Y., et al. (2003). The Wnt/beta-catenin- > Pitx2 pathway controls the turnover of Pitx2 and other unstable mRNAs. Mol. Cell. 12 (5), 1201-1211. doi: 10.1016/ S1097-2765(03)00407-6

Brock, A., Krause, S., and Ingber, D. E. (2015). Control of cancer formation by intrinsic genetic noise and microenvironmental cues. Nat. Rev. Cancer 15 (8), 499-509. doi: 10.1038/nrc3959

Chang, J., Liu, F., Lee, M., Wu, B., Ting, K., Zara, J. N., et al. (2013). NF-kappaB inhibits osteogenic differentiation of mesenchymal stem cells by promoting beta-catenin degradation. Proc. Nat. Acad. Sci. U.S.A. 110 (23), 9469-9474. doi: $10.1073 /$ pnas. 1300532110

Daugherty, R. L., Serebryannyy, L., Yemelyanov, A., Flozak, A. S., Yu, H. J., Kosak, S. T., et al. (2014). alpha-Catenin is an inhibitor of transcription. Proc. Nat. Acad. Sci. U.S.A. 111 (14), 5260-5265. doi: 10.1073/pnas.1308663111

Dirnberger, D., and Seuwen, K. (2007). Signaling of human frizzled receptors to the mating pathway in yeast. PLoS One 2 (9), e954. doi: 10.1371/journal.pone.0000954

Dohlman, H. G., and Thorner, J. W. (2001). Regulation of G protein-initiated signal transduction in yeast: paradigms and principles. Annu. Rev. Biochemis. 70, 703-754. doi: 10.1146/annurev.biochem.70.1.703

Dokumcu, K., Simonian, M., and Farahani, R. M. (2018). miR4673 improves fitness profile of neoplastic cells by induction of autophagy. Cell Death Dis. 9 (11), 1068. doi: 10.1038/s41419-018-1088-6

Elowitz, M. B., Levine, A. J., Siggia, E. D., and Swain, P. S. (2002). Stochastic gene expression in a single cell. Science 297 (5584), 1183-1186. doi: 10.1126/ science.1070919

Farahani, R., Rezaei-Lotfi, S., Simonian, M., and Hunter, N. (2019). Bi-modal reprogramming of cell cycle by MiRNA-4673 amplifies human neurogenic capacity. Cell Cycle, 18, 1-21. doi: 10.1080/15384101.2019.1595873

Fiedler, M., Mendoza-Topaz, C., Rutherford, T. J., Mieszczanek, J., and Bienz, M. (2011). Dishevelled interacts with the DIX domain polymerization interface of Axin to interfere with its function in down-regulating beta-catenin. Proc. Nat. Acad. Sci. U.S.A. 108 (5), 1937-1942. doi: 10.1073/pnas.1017063108

Garcia-Muse, T., and Aguilera, A. (2016). Transcription-replication conflicts: how they occur and how they are resolved. Nat. Rev. Mol. Cell Bio. 17 (9), 553-563. doi: $10.1038 / \mathrm{nrm} .2016 .88$

Grandori, C., Gomez-Roman, N., Felton-Edkins, Z. A., Ngouenet, C., Galloway, D. A., Eisenman, R. N., et al. (2005). c-Myc binds to human ribosomal 
DNA and stimulates transcription of rRNA genes by RNA polymerase I. Nat. Cell Biol. 7 (3), 311-318. doi: 10.1038/ncb1224

He, T. C., Sparks, A. B., Rago, C., Hermeking, H., Zawel, L., da Costa, L. T., et al. (1998). Identification of c-MYC as a target of the APC pathway. Science 281 (5382), 1509-1512. doi: 10.1126/science.281.5382.1509

Houseley, J., and Tollervey, D. (2009). The many pathways of RNA degradation. Cell 136 (4), 763-776. doi: 10.1016/j.cell.2009.01.019

Julicher, F., and Bruinsma, R. (1998). Motion of RNA polymerase along DNA: a stochastic model. Biophys. J. 74 (3), 1169-1185. doi: 10.1016/ S0006-3495(98)77833-6

Jung, C. H., Ro, S. H., Cao, J., Otto, N. M., and Kim, D. H. (2010). mTOR regulation of autophagy. FEBS Lett. 584 (7), 1287-1295. doi: 10.1016/j.febslet.2010.01.017

Kim, N. G., Xu, C., and Gumbiner, B. M. (2009). Identification of targets of the Wnt pathway destruction complex in addition to beta-catenin. Proc. Nat. Acad. Sci. U.S.A. 106 (13), 5165-5170. doi: 10.1073/pnas.0810185106

Ko, M. S. (1991). A stochastic model for gene induction. J. Theor. Biol. 153 (2), 181-194. doi: 10.1016/S0022-5193(05)80421-7

Kuhn, K., Cott, C., Bohler, S., Aigal, S., Zheng, S., Villringer, S., et al. (2015). The interplay of autophagy and beta-Catenin signaling regulates differentiation in acute myeloid leukemia. Cell Death Discov. 1, 15031. doi: 10.1038/ cddiscovery.2015.31

Kwon, C., Cheng, P., King, I. N., Andersen, P., Shenje, L., Nigam, V., et al. (2011). Notch post-translationally regulates beta-catenin protein in stem and progenitor cells. Nature Cell Biol. 13 (10), 1244-1251. doi: 10.1038/ncb2313

Lee, H. K., Kwak, H. Y., Hur, J., Kim, I. A., Yang, J. S., Park, M. W., et al. (2007). beta-catenin regulates multiple steps of RNA metabolism as revealed by the RNA aptamer in colon cancer cells. Cancer Res. 67 (19), 9315-9321. doi: 10.1158/0008-5472.CAN-07-1128

MacDonald, B. T., Tamai, K., and He, X. (2009). Wnt/beta-catenin signaling: components, mechanisms, and diseases. Dev. Cell. 17 (1), 9-26. doi: 10.1016/j. devcel.2009.06.016

Malbon, C. C. (2004). Frizzleds: new members of the superfamily of G-proteincoupled receptors. Front. Biosci. 9, 1048-1058. doi: 10.2741/1308

Mao, Z., Bozzella, M., Seluanov, A., and Gorbunova, V. (2008). Comparison of nonhomologous end joining and homologous recombination in human cells. DNA Repair 7 (10), 1765-1771. doi: 10.1016/j.dnarep.2008.06.018

Maurer, U., Preiss, F., Brauns-Schubert, P., Schlicher, L., and Charvet, C. (2014). GSK-3 - at the crossroads of cell death and survival. J. Cell Sci. 127 (Pt 7), 13691378. doi: $10.1242 /$ jcs. 138057

McCrea, P. D., Turck, C. W., and Gumbiner, B. (1991). A homolog of the armadillo protein in Drosophila (plakoglobin) associated with E-cadherin. Science 254 (5036), 1359-1361. doi: 10.1126/science.1962194

Meng, Z., Moroishi, T., and Guan, K. L. (2016). Mechanisms of Hippo pathway regulation. Genes Dev. 30 (1), 1-17. doi: 10.1101/gad.274027.115

Mercurio, F., and Manning, A. M. (1999). NF-kappaB as a primary regulator of the stress response. Oncogene 18 (45), 6163-6171. doi: 10.1038/ sj.onc. 1203174

Mikeladze-Dvali, T., Wernet, M. F., Pistillo, D., Mazzoni, E. O., Teleman, A. A., Chen, Y. W., et al. (2005). The growth regulators warts/lats and melted interact in a bistable loop to specify opposite fates in Drosophila R8 photoreceptors. Cell 122 (5), 775-787. doi: 10.1016/j.cell.2005.07.026

Mitosch, K., Rieckh, G., and Bollenbach, T. (2017). Noisy response to antibiotic stress predicts subsequent single-cell survival in an acidic environment. Cell Syst. 4 (4), 393-403 e5. doi: 10.1016/j.cels.2017.03.001

Nelson, W. J. (2008). Regulation of cell-cell adhesion by the cadherin-catenin complex. Biochem. Soc. Trans. 36 (Pt 2), 149-155. doi: 10.1042/BST0360149

Ozbudak, E. M., Thattai, M., Kurtser, I., Grossman, A. D., and van Oudenaarden, A. (2002). Regulation of noise in the expression of a single gene. Nat. Genet. 31 (1), 69-73. doi: 10.1038/ng869

Pauklin, S., and Vallier, L. (2013). The cell-cycle state of stem cells determines cell fate propensity. Cell 155 (1), 135-147. doi: 10.1016/j.cell.2013.08.031

Pourquie, O. (2003). The segmentation clock: converting embryonic time into spatial pattern. Science 301 (5631), 328-330. doi: 10.1126/science.1085887

Raser, J. M., and O'Shea, E. K. (2004). Control of stochasticity in eukaryotic gene expression. Science 304 (5678), 1811-1814. doi: 10.1126/science.1098641

Raser, J. M., and O'Shea, E. K. (2005). Noise in gene expression: origins, consequences, and control. Science 309 (5743), 2010-2013. doi: 10.1126/ science. 1105891
Rezaei-Lotfi, S., Hunter, N., and Farahani, R. M. (2019). Coupled cycling programs multicellular self-organization of neural progenitors. Cell Cycle 18 (17), 20402054. doi: $10.1080 / 15384101.2019 .1638692$

Roh, M. S., Eom, T. Y., Zmijewska, A. A., De Sarno, P., Roth, K. A., and Jope, R. S. (2005). Hypoxia activates glycogen synthase kinase-3 in mouse brain in vivo: protection by mood stabilizers and imipramine. Biol. Psychiatry 57 (3), 278-286. doi: 10.1016/j.biopsych.2004.10.039

Ross, J. (1996). Control of messenger RNA stability in higher eukaryotes. Trends Genet. 12 (5), 171-175. doi: 10.1016/0168-9525(96)10016-0

Sadot, E., Geiger, B., Oren, M., and Ben-Zeev, A. (2001). Down-regulation of beta-catenin by activated p53. Mol. Cell. Biol. 21 (20), 6768-6781. doi: 10.1128/ MCB.21.20.6768-6781.2001

Salic, A., Lee, E., Mayer, L., and Kirschner, M. W. (2000). Control of beta-catenin stability: reconstitution of the cytoplasmic steps of the wnt pathway in Xenopus egg extracts. Mol. Cell. 5 (3), 523-532. doi: 10.1016/S1097-2765(00)80446-3

Samoilov, M., Plyasunov, S., and Arkin, A. P. (2005). Stochastic amplification and signaling in enzymatic futile cycles through noise-induced bistability with oscillations. Proc. Nat. Acad. Sci. U.S.A. 102 (7), 2310-2315. doi: 10.1073/ pnas.0406841102

Samoilov, M. S., Price, G., and Arkin, A. P. (2006). From fluctuations to phenotypes: the physiology of noise. Sci. STKE 2006 (366), re17. doi: 10.1126/ stke.3662006re17

Schmidt, E. V. (2004). The role of c-myc in regulation of translation initiation. Oncogene 23 (18), 3217-3221. doi: 10.1038/sj.onc.1207548

Schreck, R., Albermann, K., and Baeuerle, P. A. (1992). Nuclear factor kappa B: an oxidative stress-responsive transcription factor of eukaryotic cells (a review). Free Radic. Res. Commun. 17 (4), 221-237. doi: 10.3109/10715769209079515

Serebryannyy, L. A., Yemelyanov, A., Gottardi, C. J., and de Lanerolle, P. (2017). Nuclear alpha-catenin mediates the DNA damage response via beta-catenin and nuclear actin. J. Cell Sci. 130 (10), 1717-1729. doi: 10.1242/jcs.199893

Shamir, M., Bar-On, Y., Phillips, R., and Milo, R. (2016). SnapShot: timescales in Cell Biology. Cell 164 (6), 1302-1 e1. doi: 10.1016/j.cell.2016.02.058

Shtutman, M., Zhurinsky, J., Simcha, I., Albanese, C., D’Amico, M., Pestell, R., et al. (1999). The cyclin D1 gene is a target of the beta-catenin/LEF-1 pathway. Proc. Nat. Acad. Sci. U.S.A. 96 (10), 5522-5527. doi: 10.1073/pnas.96.10.5522

Siegal, M. L., and Bergman, A. (2002). Waddington's canalization revisited: developmental stability and evolution. Proc. Nat. Acad. Sci. U.S.A. 99 (16), 10528-10532. doi: 10.1073/pnas.102303999

Skourti-Stathaki, K. (2014). Proudfoot NJ. A double-edged sword: R loops as threats to genome integrity and powerful regulators of gene expression. Genes Dev. 28 (13), 1384-1396. doi: 10.1101/gad.242990.114

Spencer, S. L., Gaudet, S., Albeck, J. G., Burke, J. M., and Sorger, P. K. (2009). Nongenetic origins of cell-to-cell variability in TRAIL-induced apoptosis. Nature. 459 (7245), 428-432. doi: 10.1038/nature08012

Spizizen, J. (1958). Transformation of Biochemically Deficient Strains of Bacillus Subtilis by Deoxyribonucleate. Proc. Nat. Acad. Sci. U.S.A. 44 (10), 1072-1078. doi: $10.1073 /$ pnas.44.10.1072

Suel, G. M., Garcia-Ojalvo, J., Liberman, L. M., and Elowitz, M. B. (2006). An excitable gene regulatory circuit induces transient cellular differentiation. Nature 440 (7083), 545-550. doi: 10.1038/nature04588

Tempe, D., Casas, M., Karaz, S., Blanchet-Tournier, M. F., and Concordet, J. P. (2006). Multisite protein kinase A and glycogen synthase kinase 3beta phosphorylation leads to Gli3 ubiquitination by SCFbetaTrCP. Mol. Cell. Biol. 26 (11), 4316-4326. doi: 10.1128/MCB.02183-05

Thompson, B. A., Tremblay, V., Lin, G., and Bochar, D. A. (2008). CHD8 is an ATP-dependent chromatin remodeling factor that regulates beta-catenin target genes. Mol. Cell. Biol. 28 (12), 3894-3904. doi: 10.1128/MCB.00322-08

Thornton, B. R., and Toczyski, D. P. (2003). Securin and B-cyclin/CDK are the only essential targets of the APC. Nat. Cell Biol. 5 (12), 1090-1094. doi: 10.1038/ ncb1066

Ulloa, F., Itasaki, N., and Briscoe, J. (2007). Inhibitory Gli3 activity negatively regulates Wnt/beta-catenin signaling. Curr. Boil. 17 (6), 545-550. doi: 10.1016/j.cub.2007.01.062

van Riggelen, J., Yetil, A., and Felsher, D. W. (2010). MYC as a regulator of ribosome biogenesis and protein synthesis. Nat. Rev. Cancer 10 (4), 301-309. doi: $10.1038 / \mathrm{nrc} 2819$

Vodermaier, H. C. (2004). APC/C and SCF: controlling each other and the cell cycle. Curr. Biol. 14 (18), R787-RR96. doi: 10.1016/j.cub.2004.09.020 
Volfson, D., Marciniak, J., Blake, W. J., Ostroff, N., Tsimring, L. S., and Hasty, J. (2006). Origins of extrinsic variability in eukaryotic gene expression. Nature 439 (7078), 861-864. doi: 10.1038/nature04281

Wang, B., and Li, Y. (2006). Evidence for the direct involvement of \{beta\}TrCP in Gli3 protein processing. Proc. Nat. Acad. Sci. U.S.A. 103 (1), 33-38. doi: 10.1073/pnas.0509927103

Wu, D., and Pan, W. (2010). GSK3: a multifaceted kinase in Wnt signaling. Trends Biochem. Sci. 35 (3), 161-168. doi: 10.1016/j.tibs.2009.10.002

Wu, C. I., Hoffman, J. A., Shy, B. R., Ford, E. M., Fuchs, E., Nguyen, H., et al. (2012). Function of Wnt/beta-catenin in counteracting Tcf3 repression through the Tcf3-beta-catenin interaction. Development 139 (12), 2118-2129. doi: 10.1242/ dev.076067

Xie, J., Ponuwei, G. A., Moore, C. E., Willars, G. B., Tee, A. R., and Herbert, T. P. (2011). cAMP inhibits mammalian target of rapamycin complex-1 and -2 (mTORC1 and 2) by promoting complex dissociation and inhibiting mTOR kinase activity. Cell. Signal. 23 (12), 1927-1935. doi: 10.1016/j. cellsig.2011.06.025

Zavadil, J., Cermak, L., Soto-Nieves, N., and Bottinger, E. P. (2004). Integration of TGF-beta/Smad and Jagged1/Notch signalling in epithelial-to-mesenchymal transition. EMBO J. 23 (5), 1155-1165. doi: 10.1038/sj.emboj.7600069
Zeller, K. I., Zhao, X., Lee, C. W., Chiu, K. P., Yao, F., Yustein, J. T., et al. (2006). Global mapping of $\mathrm{c}$-Myc binding sites and target gene networks in human B cells. Proc. Nat. Acad. Sci. U.S.A. 103 (47), 17834-17839. doi: 10.1073/ pnas.0604129103

Zhang, M., Wang, M., Tan, X., Li, T. F., Zhang, Y. E., and Chen, D. (2010). Smad3 prevents beta-catenin degradation and facilitates beta-catenin nuclear translocation in chondrocytes. J. Biol. Chem. 285 (12), 8703-8710. doi: 10.1074/ jbc.M109.093526

Conflict of Interest: The authors declare that the research was conducted in the absence of any commercial or financial relationships that could be construed as a potential conflict of interest.

Copyright (c) 2019 Rezaei-Lotfi, Hunter and Farahani. This is an open-access article distributed under the terms of the Creative Commons Attribution License (CC BY). The use, distribution or reproduction in other forums is permitted, provided the original author(s) and the copyright owner(s) are credited and that the original publication in this journal is cited, in accordance with accepted academic practice. No use, distribution or reproduction is permitted which does not comply with these terms. 